\title{
Quality and Performance of Permitted Explosives and Detonators used in SCCL Mines in India
}

\author{
Rajeev Ranjan Singh* \\ CSIR-Central Institute of Mining \& Fuel Research, India
}

ISSN: 2578-0255

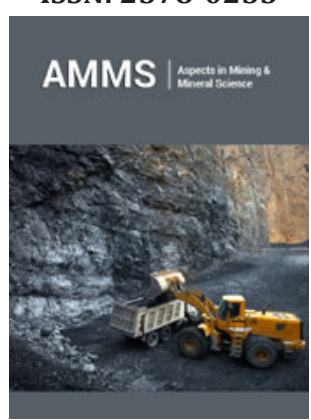

*Corresponding author: Rajeev Ranjan Singh, Chief Scientist, CSIR-Central Institute of Mining \& Fuel Research, India

Submission: 眥 November 06, 2019

Published: 漈January 07, 2020

Volume 4 - Issue 3

How to cite this article: Rajeev Ranjan Singh. Quality and Performance of Permitted Explosives and Detonators used in SCCL Mines in India. Aspects Min Miner Sci.4(3). AMMS.000587.2020.

DOI: 10.31031/AMMS.2020.04.000587

Copyright@ Rajeev Ranjan Singh, This article is distributed under the terms of the Creative Commons Attribution 4.0 International License, which permits unrestricted use and redistribution provided that the original author and source are credited.

\begin{abstract}
Blast performance depends on geo-mechanical properties of rock, detonation properties of explosive systems and blast design parameters. For a mine having nearly constant geo-mechanical parameters and have fixed optimized blast pattern, the blast results are very much dependent on the quality of explosive products. For consistent blast results, quality of explosive should be consistent. Mine management needs to ensure that performance and quality of an explosive system are the same as that has been predicated or stated by the supplier. Periodic check of the quality and performance parameters of the explosives and accessories of different manufacturers collected from the users' magazines/blasting face serve as a useful mechanism towards ensuring safety and quality of such products. In this paper, quality evaluation of slurry and emulsion permitted explosives and permitted detonators of different firms supplied in SCCL were done at SCCL site and their impact on performances in underground coal mines were observed. Results of studies on post detonation toxic fumes were also done with the help of Rescue team of SCCL in presence of CIMFR Scientist which gives the real picture of toxic contents of explosives used in underground coal mines where working personals are allowed to work after 5 minutes of blasting. Deviations in the quality of explosive and detonator parameters were found which has direct impact on the underground coal production in SCCL mines. Based on the results of studies and CIMFR advice, explosive manufacturers improved the quality of their explosive products time to time aimed for getting desired coal production safely underground coal mines of SCCL in India.
\end{abstract}

Keywords: Blast performance; Detonation; Safety; Underground coal production; SCCL mines, Blasting; Quality evaluation; Quality of explosives; Permitted explosives; Permitted detonators; Slurry and emulsion; Magazines/blasting face

Abbreviations: DGMS: Directorate General of Mines Safety; TM: Testing Memorandum; VOD: Velocity of Detonation; AGS: Air Gap Sensitivity

\section{Introduction}

Permitted explosives and detonators are explosive products which are approved by Directorate General of Mines Safety (DGMS) for use in underground coal mines where there is likely presence of inflammable atmospheres of coal dust and firedamp. Therefore, they are designed to meet the statutory requirements with respect to their incendivity as well as other safety and performance parameters for their safe and efficient use in underground coal mines [1]. Electric detonators containing highly sensitive initiatory explosive, as their primary and base charges are susceptible to accidental initiation during manufacture, storage, transportation and use due to unavoidable vibration, jerk, drop, stray currents etc. Permitted detonators should possess circuit continuity, uniform electrical characteristics, series firing characteristics and adequate strength for their unfailing detonation and initiation of the cap sensitive explosives. They should also meet no fire current safety requirements as a safeguard against stray currents. Delay elements made with pyrotechnic delay compositions used in electric delay detonators have inherent scattering in their delay timings. It is desirable to use precise delay timing detonators to achieve better fragmentation with less vibration and noise. Manufacturing of delay detonators demands high level of quality control to keep the scattering low so that overlapping in delay timings between adjacent delays could be avoided. Similarly, permitted explosives are required to meet the statutory requirements of incendivity along with sensitivity (e.g. cap sensitivity, air gap sensitivity, continuity of detonation, etc.), post detonation fumes and other related parameters. They should have their performance parameters matching with the users' expectations. As such, permitted explosives and permitted detonators should conform to a high degree of safety as per standards, stipulated 
norms, DGMS guidelines etc. Once the permitted explosive and detonator are approved by DGMS, it is the responsibility of the manufacturer to maintain their quality parameters within their tolerance limits.

There has been a rapid increase in the number of explosive manufacturers supplying bulk explosives, cartridge explosives and accessories as per the use in opencast and underground mines. A large number of manufacturers in the country and availability of various types of explosives provide flexibility in the selection of the explosives to suit various blasting applications. When selecting an explosive system, two main aims are to maximize safety and to minimize the total cost of mining. Although, stiff competition amongst the explosive suppliers has brought the prices of the explosives items down, but there has been concern over the quality of the explosives being supplied to the mining industry. Therefore, required level of safety with adequate sensitivity and optimum performance are essential requirements for commercial explosive products, which can be achieved consistently by maintaining the quality of the explosives. Blast performance depends on geomechanical properties of rock, detonation properties of explosive systems and blast design parameters. For a mine having nearly constant geo-mechanical parameters and have fixed optimized blast pattern, the blast results are very much dependent on the quality of explosive products. For consistent blast results, quality of explosive should be consistent. Mine management needs to ensure that performance and quality of an explosive system are the same as that has been predicated or stated by the supplier. Periodic check of the quality and performance parameters of the explosives and accessories of different manufacturers collected from the users' magazines/blasting face serve as a useful mechanism towards ensuring safety and quality of such products [2]. In India, three types of permitted explosives, namely (i) permitted (ordinary) or $\mathrm{P}_{1}$ explosive (ii) permitted (equivalent to sheathed) or $\mathrm{P}_{3}$ explosive (iii) permitted (for solid blasting) or $\mathrm{P}_{5}$ explosive, are commonly manufactured and approved for use in underground coal mines. Similarly, permitted detonators are of two types: instantaneous and delay detonators i.e. CED and CDD designed as per the requirement of use in cut/free face or in solid blasting. Incendivity test described in IS:6609 (Part II/Sec 2) for categorization of permitted explosives into $\mathrm{P}_{1}, \mathrm{P}_{3}$ and $\mathrm{P}_{5}$ groups in India is similar to Testing Memorandum (TM 2) of UK. This paper deals the performance and quality parameters of permitted explosives and detonators used in SCCL underground coal mines.

\section{Experimentation}

To check the performance and safety parameters of permitted explosive and detonators used in underground coal mines following methods were adopted during their evaluation.

\section{Details of the studies on permitted explosives}

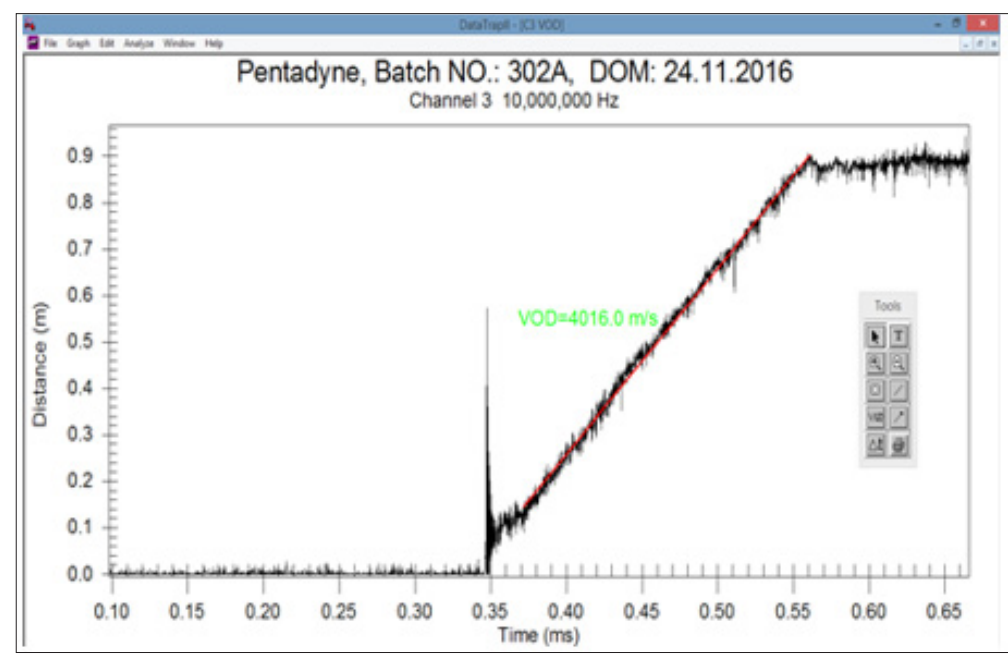

Figure 1: VOD graph of P5 slurry explosive.

For determination of air gap sensitivity of permitted explosives, trials under Full Cartridge Test conditions were carried out. In Full Cartridge Test, two full cartridges were taken, and one explosive cartridge was primed with a permitted detonator. The primer cartridge served as donor cartridge and a second cartridge, without priming (i.e. receptor cartridge) was placed in line with donor cartridge at a prefixed gap between the two cartridges. Donor and receptor cartridges with air gap in between them were wrapped in three-fold paper and fired in open field. The air gap between the cartridges was measured from shoulder to shoulder. The maximum air gap at which both donor and receptor cartridges detonated completely in five consecutive trials was taken as the air gap sensitivity (AGS) of the explosive. As per DGMS Circular (Approval) no. 06 dated 17.11.2014, all permitted slurry or emulsion explosives are required to have minimum $2 \mathrm{~cm}$ air gap sensitivity in full cartridge test conditions. Therefore, five trials with $2 \mathrm{~cm}$ air gap between two full cartridges of each explosive sample were conducted. Velocity of detonation (VOD) of explosive samples was evaluated by VOD Mate/Data Trap II (a continuous VOD meter manufactured by M/s Instantel /M/s MREL, Canada). VOD Mate/ 
Data Trap II works by providing a constant current source to drive a high resistance VOD sensing co-axial cable. The VOD sensing cable was placed in close contact with the explosive and was then shorted and consumed by the explosive's detonation front. The VOD Mate/ Data Trap II recorded continuously the change in resistivity of VOD sensing cable as it was consumed to calculate the VOD. Data recorded in VOD Mate/Data Trap II were then analyzed with software supplied with the instrument. The slope of the best-fit regression line gave the VOD value [3-5]. Average VOD values given in the report were calculated judiciously considering different VOD values obtained with VOD Mate/Data Trap II. A typical VOD graph of P5 slurry explosive has been shown in Figure 1. Standard density solutions were used for determination of the density of explosives. In this method, a small amount of an explosive taken from the explosive cartridge was placed in the density solutions. The density of the solution, in which the explosive sample floats inside it, was then measured by Hydrometer and was taken equal to the density of the explosive sample.

\section{Details of the studies on permitted detonators}

Resistance of 5 nos. of detonators of each sample was measured with their full lead--wire lengths using appropriate Multimeter/ Scope meter. While measuring the resistance, detonators were kept inside a protective chamber as shown in Figure 2. Because of inherent variations in resistance of fuse heads and lead wires, resistance of detonators may vary. Electric detonators should have consistent electrical resistance with least deviations. In general, it is expected that the variation in resistance should be within $\pm 10 \%$ of their average values. After measurement of electrical resistance, detonators were checked for their no fire current safety by supplying a fixed direct current of $180 \mathrm{~mA}$ for 300 seconds using 'No Fire Current Meter' as shown in Figure 3. Electric detonators should be able to withstand the passage of $180 \mathrm{~mA}$ direct current (DC) for 300 seconds without getting detonated [6]. This test is the safeguard of detonators against a stray/static current generated by any source in the mine.

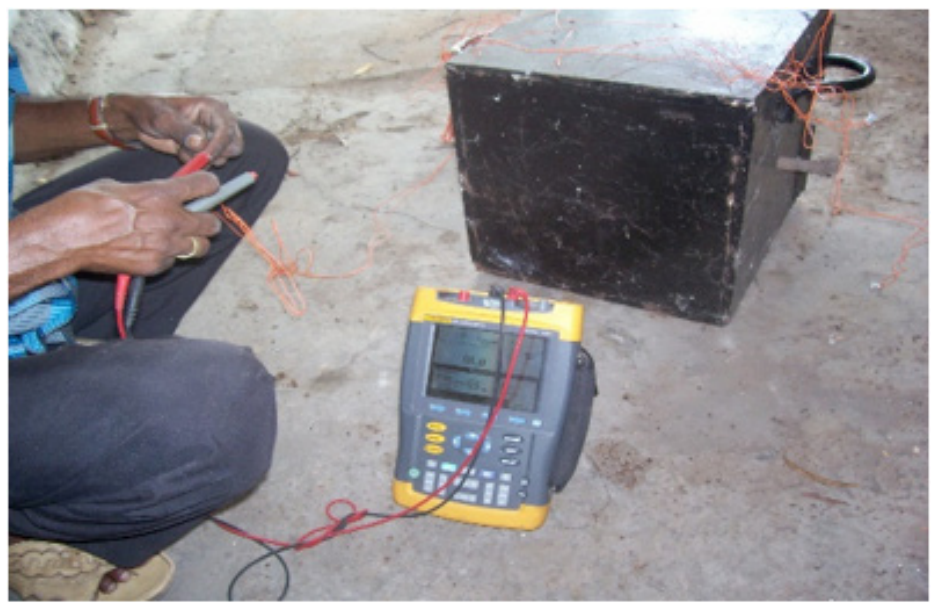

Figure 2: Measurement of electrical resistance.

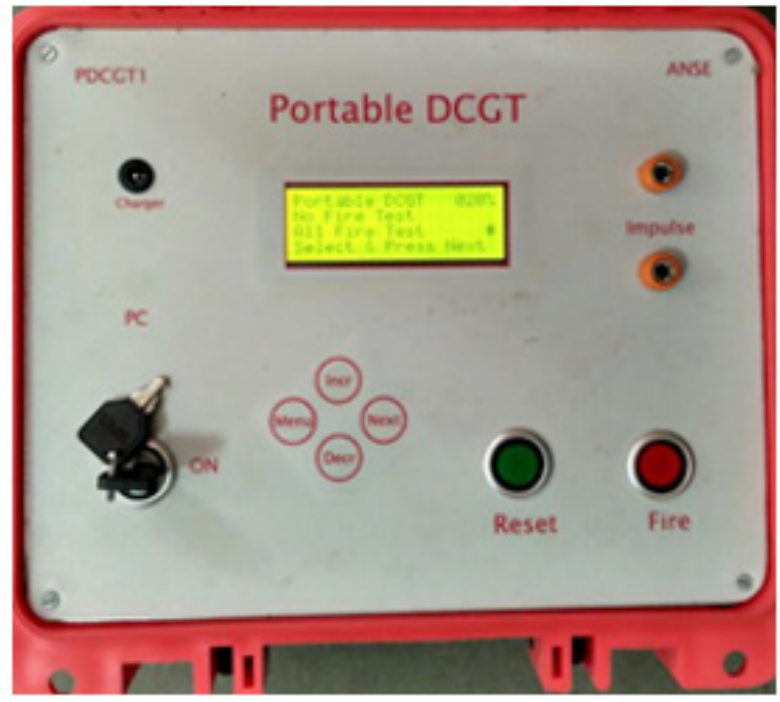

Figure 3: Instrument for no fire current. 
In order to check the series firing characteristics, twenty numbers of the detonator with their full length of lead wires were connected in series and then connected across the terminals of a Series Firing Meter, a DC current generator. The instrument, shown in Figure 4, determines the total resistance of the firing circuit and compensates it automatically to allow a fixed direct current of 1.2 amperes to flow through the detonator series for specified time duration of 4 milliseconds. All 20 detonators connected in series should get fired in each trial to ensure their unfailing detonation during the actual usage. Strength is the important parameter of detonators to ensure proper detonation of explosive cartridges during their actual usage. Strength of the detonator samples was measured using lead plate method as per IS 6609 (Part III). Lead plates, each of $5.0 \mathrm{~mm}$ thickness and $4 \mathrm{~cm}$ square size, were placed on top of the holes on the lower plate of the firing frame. One detonator was placed on top of each plate vertically with the base of the detonator shell in good contact with the lead plate. Figure 5 shows the photograph of the firing frame having 10 compartments for firing 10 detonators at a time. Detonators were connected in series and fired at a time using suitable exploder. The markings (perforations, craters or otherwise) produced on the lead plates were then examined and measured for classification of strength of detonators as per IS 6609 (Part III).

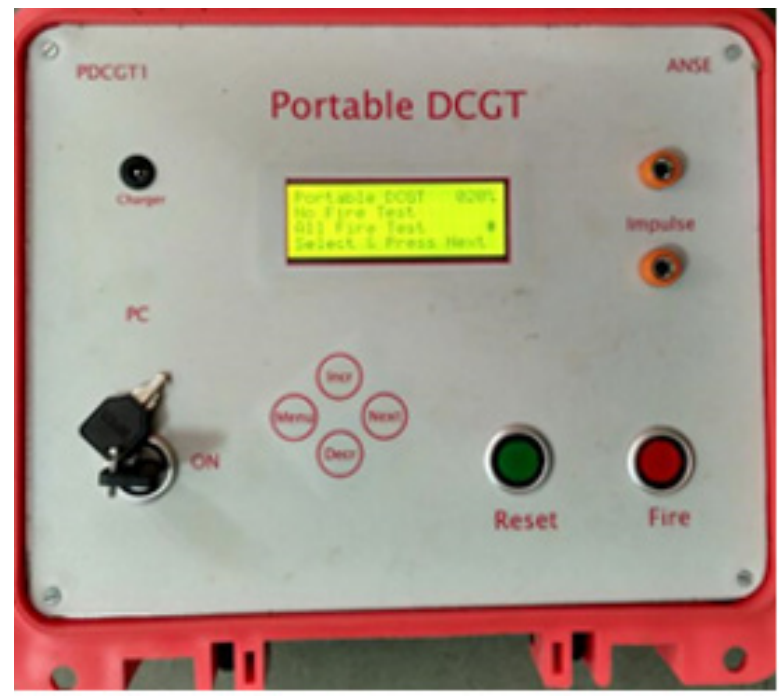

Figure 4: Instrument for series firing current.

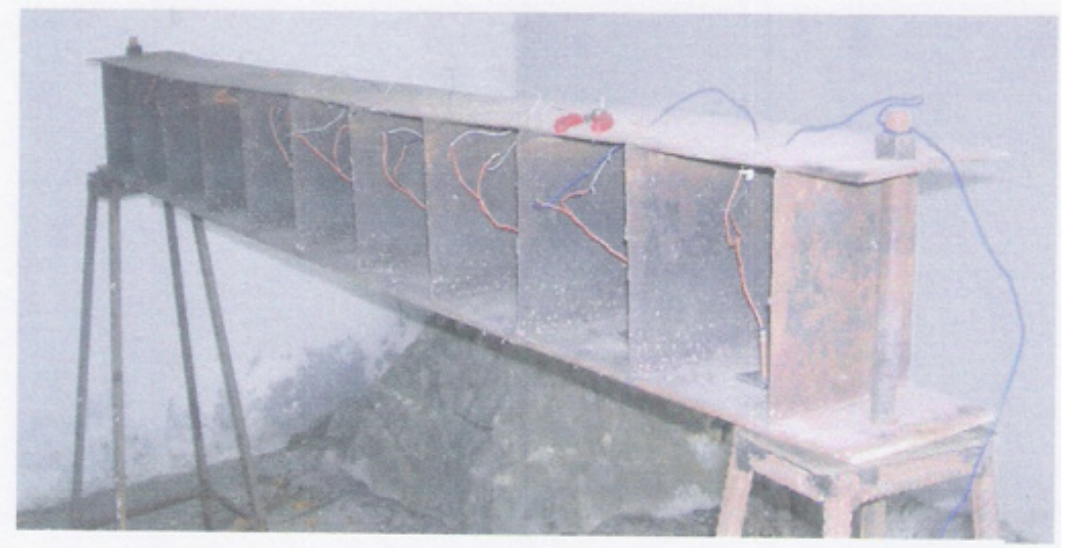

Figure 5: Firing frame of strength test.

In order to assess the handling safety of the detonator samples, they were checked for drop and snatch tests. The detonators, with their lead wires cut down to $20 \mathrm{~cm}$ length, were dropped through a GI pipe of $40 \mathrm{~mm}$ inner dia. from a height of $2 \mathrm{~m}$ upon an MS plate inside a protective chamber (Figure 6) one at a time. Care was taken to ensure that the detonators should fall vertically with the bottom portion downward. For checking safety against sudden jerk, the lead wires of the detonators were cut to $1.0 \mathrm{~m}$ length and passed through a small hole on a steel plate and tied to a $5 \mathrm{Kg}$ weight kept on a platform, so that when dropped, the weight could fall from a height of half a meter giving a sudden jerk on the lead wires. Figure 7 shows the set-up used for snatch test [7]. Dropping of detonator 
from a working height is very common and detonator every time during straightening of lead wires before making the primer cartridge for blasting may experience a sudden jerk. So, to avoid any accidental firing in actual usage condition, there should be no detonation during drop and snatch test in any trial. Delay timings of delay detonators (i.e. except instantaneous \& CDD-0 delay) were measured using suitable delay timer as shown in Figure 8. Delay detonators should have minimum variation in their delay timings to avoid their overlapping possibilities. Overlapping in delay firing is undesirable from production as well as safety point of view [8].

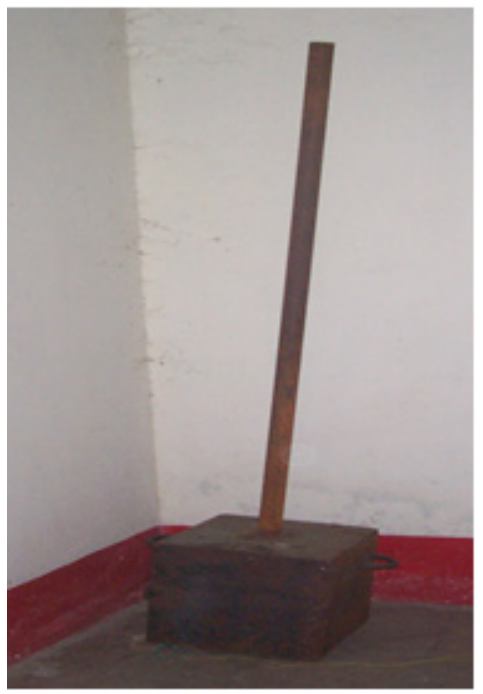

Figure 6: Set-up for drop test.
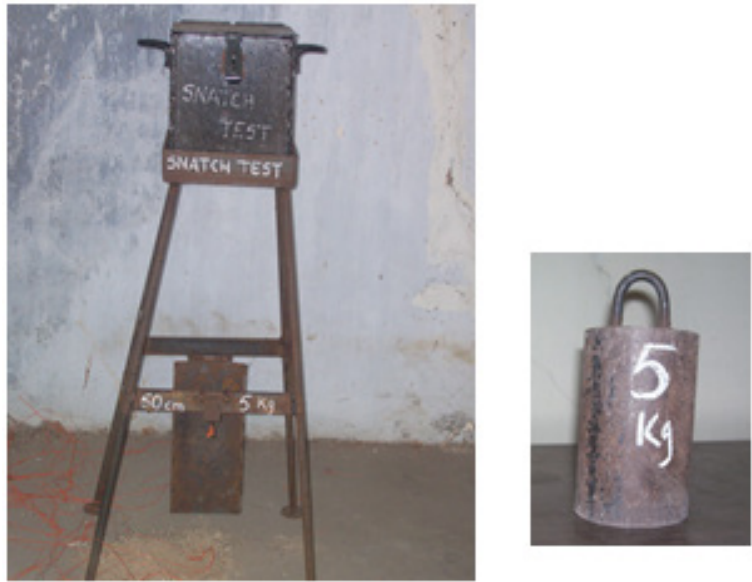

Figure 7: Set-up for snatch test.

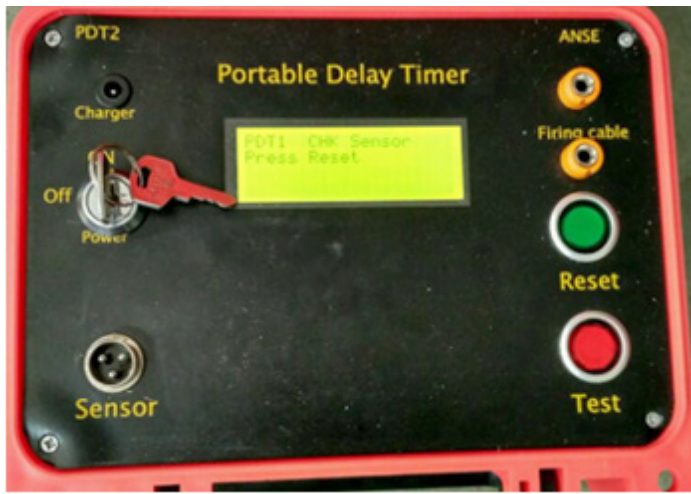

Figure 8: Instrument for measurement of delay timing. 


\section{Results of Studies}

Results of major performance and safety parameters of permitted explosives which were checked in SCCL test site are presented in Table 1.

\section{Discussion on the Results}

Periodic evaluation on the quality of permitted explosives and detonators supplied to $\mathrm{M} / \mathrm{s}$ Singareni Collieries Company
Limited by different manufacturers are aimed at ascertaining their conformity to the desired/ declared quality, safety and performance characteristics. Periodic evaluation of permitted explosives and detonators detailed in Table $1 \& 2$ were checked for their different quality parameters as mentioned in section 3.0 of this paper. Evaluation of quality parameters of permitted explosives and detonators samples revealed useful information on their conformity or deviation from declared/expected quality parameters.

Table 1: Results of different parameters of explosive samples checked in SCCL.

\begin{tabular}{|c|c|c|c|c|c|}
\hline Sl. No. & $\begin{array}{l}\text { Type of Explo- } \\
\text { sive }\end{array}$ & $\begin{array}{l}\text { No. of samples } \\
\text { Checked }\end{array}$ & $\begin{array}{c}\text { Results of Air Gap Sensitiv- } \\
\text { ity (AGS) }\end{array}$ & $\begin{array}{l}\text { Results of Velocity of Deto- } \\
\text { nation (VOD). }\end{array}$ & Results of Density \\
\hline 1 & $\mathrm{P}_{1}$ Slurry & 6 & $\begin{array}{l}5 \text { Samples: Passed } \\
1 \text { Sample: Failed }\end{array}$ & $\begin{array}{l}5 \text { Samples: Passed } \\
1 \text { Sample: Failed }\end{array}$ & 6 Samples: Passed \\
\hline 2 & $\mathrm{P}_{5}$ Slurry & 14 & $\begin{array}{l}11 \text { Samples: Passed } \\
3 \text { Samples: Failed }\end{array}$ & $\begin{array}{l}6 \text { Samples: Passed } \\
8 \text { Samples: Failed }\end{array}$ & $\begin{array}{l}12 \text { Samples: Passed } \\
2 \text { Samples: Failed }\end{array}$ \\
\hline 3 & $\mathrm{P}_{1}$ Emulsion & 10 & $\begin{array}{l}8 \text { Samples: Passed } \\
1 \text { Sample: Failed }\end{array}$ & $\begin{array}{l}5 \text { Samples: Passed } \\
5 \text { Samples: Failed }\end{array}$ & 10 Samples: Passed \\
\hline 4 & $\mathrm{P}_{5}$ Emulsion & 7 & $\begin{array}{l}6 \text { Samples: Passed } \\
1 \text { Sample: Failed }\end{array}$ & 7 Samples: Passed & 7 Samples: Passed \\
\hline
\end{tabular}

Table 2: Results of different parameters of permitted detonators checked in SCCL. N.A.: Not Applicable.

\begin{tabular}{|c|c|c|c|c|c|c|c|c|c|}
\hline Sl. No. & $\begin{array}{l}\text { Type of permitted } \\
\text { detonators }\end{array}$ & $\begin{array}{l}\text { No. of } \\
\text { Samples } \\
\text { checked }\end{array}$ & $\begin{array}{l}\text { Electrical } \\
\text { Resistance }\end{array}$ & $\begin{array}{l}\text { No Fire } \\
\text { Current }\end{array}$ & $\begin{array}{l}\text { Series } \\
\text { Firing } \\
\text { Current }\end{array}$ & $\begin{array}{l}\text { Delay } \\
\text { Timing }\end{array}$ & Drop & Snatch & Strength \\
\hline 1 & $\begin{array}{l}\text { Instantaneous } \\
\text { Copper Electric } \\
\text { Detonator (CED) }\end{array}$ & 16 & 16: Passed & 16: Passed & 16: Passed & N.A. & 16: Passed & 16: Passed & $\begin{array}{l}\text { 16: Passed (All } \\
\text { B.1 Class) }\end{array}$ \\
\hline 2 & $\begin{array}{c}\text { Permitted/Coal } \\
\text { Delay Detonator } \\
\text { (CDD No.0) }\end{array}$ & 17 & 17: Passed & 17: Passed & $\begin{array}{l}\text { 15: Passed } \\
\text { 2: Failed }\end{array}$ & N.A. & 17: Passed & 17: Passed & $\begin{array}{l}\text { 17: Passed (All } \\
\text { B.1 Class) }\end{array}$ \\
\hline 3 & $\begin{array}{l}\text { Permitted/Coal De- } \\
\text { lay Detonator (CDD } \\
\text { No. 1-6) }\end{array}$ & 65 & 65: Passed & 65: Passed & $\begin{array}{l}\text { 60: Passed } \\
\text { 5: Failed }\end{array}$ & $\begin{array}{c}\text { 21: } \\
\text { Passed } \\
\text { 44: Failed }\end{array}$ & 65: Passed & $\begin{array}{l}\text { 64: Passed } \\
\text { 1: Failed }\end{array}$ & $\begin{array}{l}\text { 65: Passed (All } \\
\text { B.1 Class) }\end{array}$ \\
\hline
\end{tabular}

\section{Discussion on the results of permitted explosives}

Permitted explosives should meet minimum acceptance criteria of $2 \mathrm{~cm}$ air gap sensitivity (under Full Cartridge Test conditions) set by DGMS vide Circular (Approval) no. 06 dated 17.11.2014 to ensure their satisfactory and consistent initiation during their actual usage in underground coal mines. Their velocity of detonation and density should be in accordance with the purchase order issued by SCCL [9]. Assessment of air gap sensitivity under DGMS recommended full cartridge test conditions in open unconfined condition revealed that out of six samples of permitted $\mathrm{P}_{1}$ slurry explosives only five samples were able to meet the minimum statutory requirement of $2 \mathrm{~cm}$ air gap sensitivity in open unconfined under full cartridge test conditions. Similarly, out of fourteen samples of permitted $\mathrm{P}_{5}$ slurry explosives only eleven samples passed $2 \mathrm{~cm}$ air gap sensitivity and out of ten samples of permitted $\mathrm{P}_{1}$ emulsion explosives nine samples passed $2 \mathrm{~cm}$ air gap sensitivity. Whereas, out of seven samples of permitted $\mathrm{P}_{5}$ emulsion explosives only six samples passed $2 \mathrm{~cm}$ air gap sensitivity which are depicted in Figure 9 mentioned below.

Average VOD values of $\mathrm{P}_{1}$ slurry and $\mathrm{P}_{5}$ slurry explosives should be in the range of $3500 \pm 400 \mathrm{~m} / \mathrm{s}$ and $3400 \pm 400 \mathrm{~m} / \mathrm{s}$ respectively as per SCCL purchase order. Similarly, average VOD value of $\mathrm{P}_{1}$ emulsion and $\mathrm{P}_{5}$ emulsion explosives should be in the range of $3700 \pm 400 \mathrm{~m} / \mathrm{s}$ and $3600 \pm 400 \mathrm{~m} / \mathrm{s}$ respectively as per SCCL purchase orders. Here, out of thirty-seven samples of permitted explosives of different types only twenty-three samples of permitted explosives satisfactorily met the quality requirement of VOD parameter which are depicted in Figure 10 mentioned below. Average density values of $\mathrm{P}_{1}$ slurry and $\mathrm{P}_{5}$ slurry explosives should be in the range of $1.10 \pm 0.05 \mathrm{~g} / \mathrm{cc}$ and average density values of $\mathrm{P}_{1}$ emulsion and $\mathrm{P}_{5}$ emulsion explosives should be in the range of $1.15 \pm 0.05 \mathrm{~g} / \mathrm{cc}$ as 
per SCCL purchase order. Out of thirty-seven samples of permitted explosives of different types thirty-five samples of permitted explosives satisfactorily met the quality requirement of density parameter and only two samples failed to meet the requirement of density which are depicted in Figure 11 mentioned below.

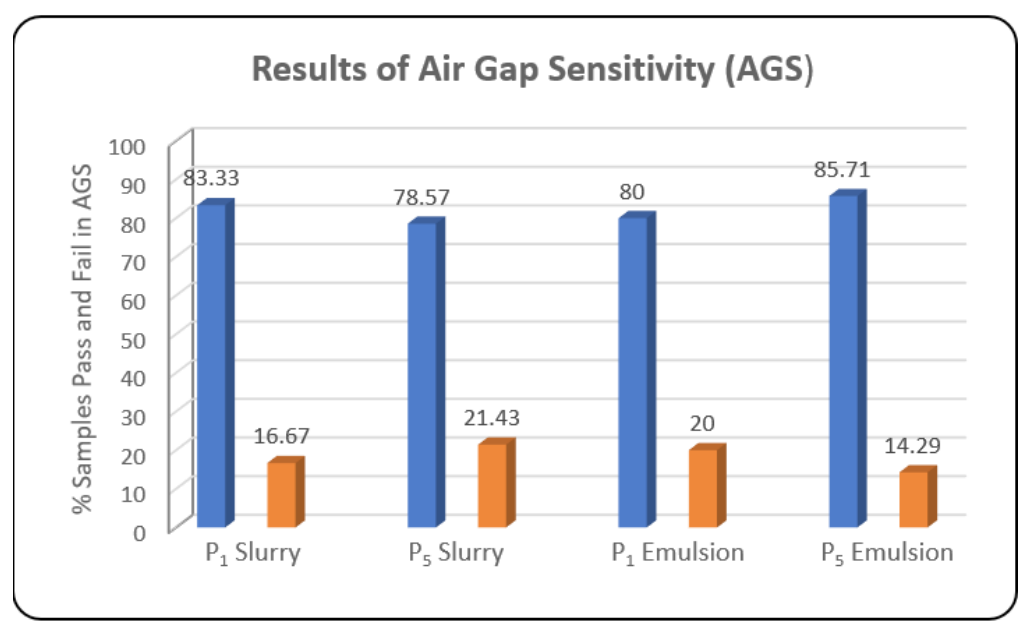

Figure 9: Histogram showing results of air gap sensitivity.

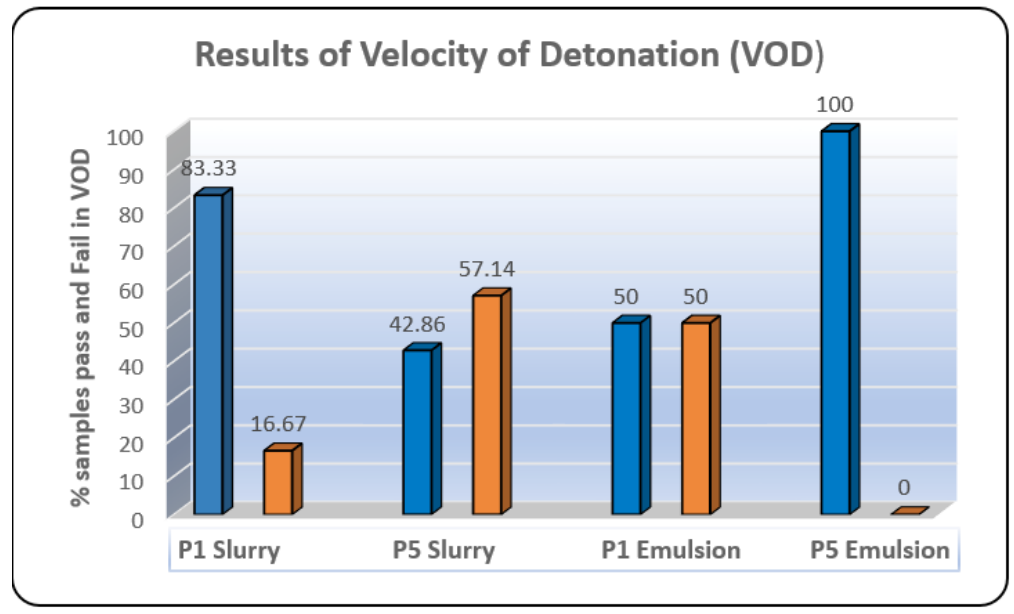

Figure 10: Histogram showing results of velocity of detonation.

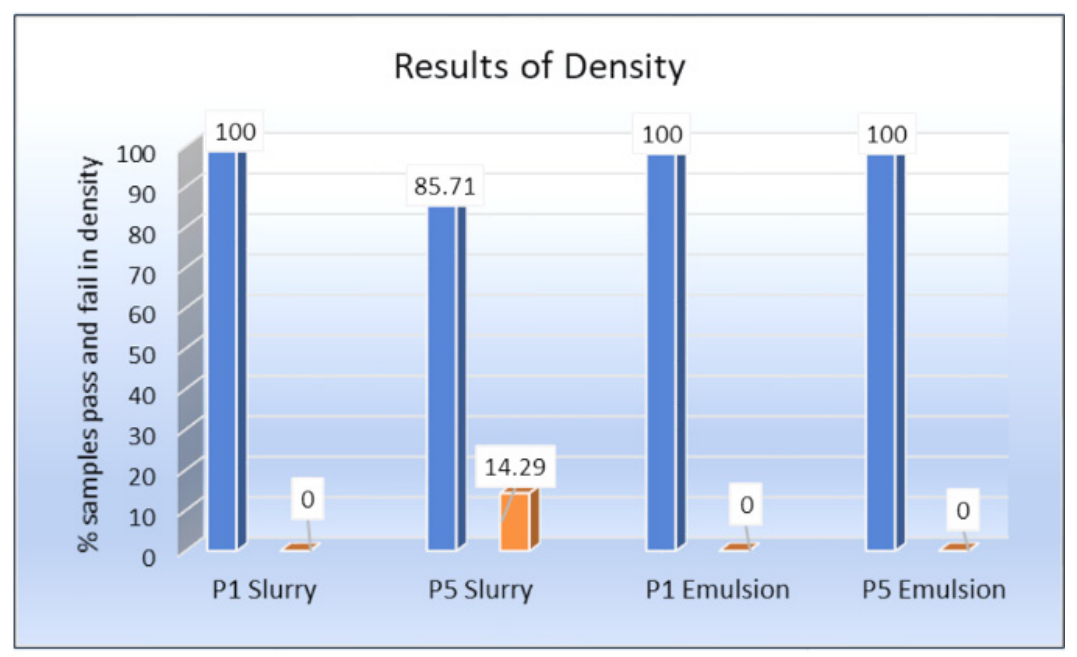

Figure 11: Histogram showing results of density. 


\section{Discussion on the results of permitted detonators}

Electric detonators are designed to withstand the passage of a pre-defined current for a reasonable period without getting detonated to make them safe against stray/static currents [10]. All ninety-eight detonators samples of four different manufacturers exhibited satisfactory no fire current safety and none of them detonated during no fire current test after application of $180 \mathrm{~mA}$ current up to 300 seconds. Therefore, all of them may be considered to possess satisfactory no fire current safety. All ninety-eight detonator samples were also found to have their resistance values within $\pm 10 \%$ of their average values and thus their resistance values may also be considered satisfactory. With the application of $1.20 \mathrm{~A}$ current for $4 \mathrm{~ms}$ during the trials for series firing current test, 20 detonators connected in series should detonate successfully. During periodic evaluation of detonator samples in SCCL, out of ninetyeight detonator samples ninety-one samples exhibited satisfactory series firing characteristics as no detonator was found undetonated in series firing current test. Seven samples of detonators failed to meet the requirement of series firing current test. Randomly selected detonator samples of different manufacturers were able to make a perforation in the $5 \mathrm{~mm}$ thick lead plate and their strength values were found to be conforming to Class 'B.1', which is higher than minimum acceptable strength value of Class 'B.3'. Thus, their strength values may be considered satisfactory for successful initiation of cap sensitive explosives. In order to assess the safety of detonators against possible drop and jerk during handling, they were checked for Drop and Snatch tests. None of the detonators of all ninety-eight samples of detonators subjected to Drop Test detonated during five trials in each test. Out of ninety-eight samples of detonators ninety-seven samples pass the snatch test whereas one sample failed in snatch test and fired in one of the five trials. Therefore, they may be considered to conforming to the desired standards for handling safety except one sample of delay detonator which failed in snatch test.

It is always desirable to have delay detonators having more precise delay timings otherwise shot holes in a solid blasting face may get blasted out of sequence, which is undesirable, unproductive as well as unsafe. Anomalies in the delay timings of the delay detonator samples of different manufacturers were observed when their average delay timings were found to be higher or lower than their nominal values and individual values were found to have overlapping possibilities with adjacent delays. Out of 98 samples of detonators checked periodically in SCCL, 16 samples were of instantaneous detonators, 17 samples were of delay no. ' 0 ' type and other 65 samples were of delay no. 1 to 5 whose delay timings were measured. 20 detonators of each delay detonator (delay no. 1 to 5) samples were checked for their delay timing. As per DGMS recommendations and BIS acceptance criteria, only deviation of $5 \%$ in delay timing is allowed in permitted delay detonators. It is clear from Table 2 that out of 65 samples of delay detonators (delay no. 1 to 5 ) only 21 samples (i.e. $32.31 \%$ ) of delay detonators have met the requirement of delay timing characteristic. Other 44 samples (i.e. $67.69 \%$ ) of delay detonators (delay no. 1 to 5) failed in delay timing property and hence they may overlap to their adjacent higher or lower delay detonators.

\section{Conclusion}

Evaluation of thirty-seven samples of permitted explosives and ninety-eight samples of permitted detonators revealed useful information on their conformity or deviation from desired quality requirements specified in relevant standards, DGMS circulars and SCCL purchase orders. Based on the results of discussion it can be concluded that out of four types of permitted explosives used in SCCL underground coalmines, only P1 Slurry and P5 Emulsion explosives were found with least deviations in their quality parameters and hence their use may result comparatively better production and productivity of underground coalmines of SCCL with greater safety than the use of P1 emulsion and P5 slurry explosives [11].

Variation in delay timing of delay detonators of different manufacturers were found and require selective use of the product in day to day solid blasting. Jumping of delay series may be found helpful to reduce the risk of out of sequence firing of the delay detonators. Based on the third-party quality monitoring programme, SCCL management suggested to the concerned manufacturers time to time to improve their explosive products for meeting the quality requirement and hence, improvements in quality parameters were observed in the subsequent visit of CIMFR team during evaluation of explosive products. Now a day, periodic evaluation of randomly selected samples of explosive products drawn from field magazines has become an essential tool for the user to watch continuously on the quality of supplied explosive products during their use for getting desired output from underground coalmines.

\section{Acknowledgement}

The author is very much thankful to the Director, CSIRCentral Institute of Mining \& Fuel Research, Dhanbad for his kind permission to publish this paper. The author also acknowledged the contributions of the entire team of CSIR-CIMFR of this project who were involved in the experimentation and helped during conducting trials in SCCL.

\section{References}

1. Indian Standard IS: 6609 (Part II/Sec 2) (1974) Methods of test for commercial blasting explosives and accessories, Part II: explosives, section 2: explosives, permitted, Indian Standard Institutions, India, pp. 3-14.

2. DGMS Circular (Approval) No. 6 dated 17.11.2014.

3. TM 2 Testing Memorandum (1988) Test and approval of explosives for use in coal mines and other mines in which flammable gas may be a hazard. Health and Safety Executives, UK, pp. 1-6.

4. International Society of Explosives Engineers (1998) Blasters' Handbook. USA.

5. Roy SK, Singh RR, Kumar R (2007) Assessment of safety, sensitivity, stability and performance characteristics of permitted explosives. Proceedings of National Workshop on Test House, Testing Procedures and Facilities in Indian Coal and Non-Coal Sector, 28: F1-F10.

6. Roy SK, Singh RR, Kumar R, Dey UK (2007) Evaluation of velocity of detonation of permitted explosives. Blasting and Fragmentation 1(1): 69-79. 
7. Pradhan M, Verma GR, Ashplya BM (2006) Evaluation of explosive performance by continuous VOD measurement in full scale blast environment. Indian Mining \& Engineering Journal 45(9): 14-17.

8. CIMFR Report on (2013) Periodic evaluation and advice on quality of permitted explosives and detonators supplied by different manufacturers to SCCL.
9. Mason CM, Aiken EGP (1972) Methods for evaluating explosives and hazardous materials. IC. 8541 USBM, India, pp: 3-7.

10. Cook MA (1974) The science of industrial explosives. Grafic Service \& Supply Inc. Publication, USA, pp. 27-87

11. Mayor R (1977) Explosives. Verlag Chemie, Weinheim, New York, USA. 